TI 2013-033/VIII

Tinbergen Institute Discussion Paper

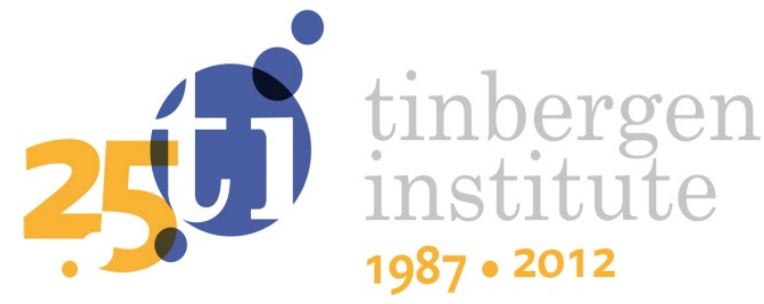

\title{
Over- and Under-Bidding in Tendering
}

Vincent A.C. van den Berg

Faculty of Economics and Business Administration, VU University Amsterdam, and Tinbergen Institute. 
Tinbergen Institute is the graduate school and research institute in economics of Erasmus University Rotterdam, the University of Amsterdam and VU University Amsterdam.

More TI discussion papers can be downloaded at http://www.tinbergen.nl

Tinbergen Institute has two locations:

Tinbergen Institute Amsterdam

Gustav Mahlerplein 117

1082 MS Amsterdam

The Netherlands

Tel.: +31(0)205251600

Tinbergen Institute Rotterdam

Burg. Oudlaan 50

3062 PA Rotterdam

The Netherlands

Tel.: +31(0)10 4088900

Fax: $+31(0) 104089031$

Duisenberg school of finance is a collaboration of the Dutch financial sector and universities, with the ambition to support innovative research and offer top quality academic education in core areas of finance.

DSF research papers can be downloaded at: http://www.dsf.nl/

Duisenberg school of finance

Gustav Mahlerplein 117

1082 MS Amsterdam

The Netherlands

Tel.: +31(0)20 5258579 


\title{
Over- and under-bidding in tendering
}

\author{
Version of 21 February 2013
}

Vincent A.C. van den Berg"

Department of Spatial Economics

VU University Amsterdam

De Boelelaan 1105

$1081 \mathrm{HV}$, Amsterdam, The Netherlands

v.a.c.vanden.berg@vu.nl

\begin{abstract}
Consider a government tendering the right to operate, for example, an airport, telecommunication network, or utility. There is an "incumbent bidder" who owns a complement or substitute facility, and one entering "new bidder". With a "standard auction" on the payment to the government, the incumbent is willing to bid higher than its expected profit from the facility as winning implies that it is a monopolist instead of a duopolist. The incumbent is therefore more likely to win. However, it tends to have a lower expected surplus unless the new bidder can never win, which occurs with "private values" when the facilities are strong complements or substitutes and always with "common values". The "standard auction" leads to an unregulated outcome which hurts consumers as tendered facilities tend to have limited competition. The government could improve the outcome by endogenously regulating using a "price auction" on the price to be asked to consumers. Now, it depends who is advantaged: with complements, the incumbent bids below its marginal cost and is more likely to win; with substitutes, it bids above and is less likely to win. The same effects occur in auctions on service quality or number of users. In many settings, the advantaged bidder always wins, and this can greatly affect the competition for the field.
\end{abstract}




\section{Introduction}

How is an auction affected if one bidder owns a complement or substitute to what is auctioned? Such a bidder will be referred to as an "incumbent"; the other bidders are "new bidders". When the government uses an auction to tender ${ }^{1}$ the right to operate an airport, one bidder could own another airport in the region, an airport that is frequent destination, or competing high-speed rail. When tendering the right to supply electricity, one bidder might already supply natural gas in that region. Further examples include auctioning a telecommunication network, a utility (e.g. water supply or waste disposal), a public transport, or mobile-internet frequencies. Similarly, in a takeover battle of a firm, a competitor or supplier might be willing to offer a premium, as taking over the firm betters its market position. In procurement, a firm that won before might have developed expertise or a firm that is currently working on many projects might have difficulty starting a new one.

This paper concentrates on a government auctioning off the right to operate a facility such as a utility or infrastructure, but the analysis has broader implications. ${ }^{2}$ The focus is on secondoffer auctions $^{3}$ with two bidders, where the winner has to (at least) match the bid of the loser. There are two facilities that are imperfect substitutes or complements. One facility is auctioned, and one bidder owns the other facility. A firm's value of owning the new facility is modelled in two ways. With "private-values", firms differ in the value, as they have different marginal costs. With "common-values", the marginal cost will be the same for both, but each bidder has a different expectation, which it updates when it learns the other's. ${ }^{4}$ This paper extends the literature by explicitly modelling advantages in tendering, and by analysing the regulatory (consumer) "price auction" (where bidders compete on the price they ask to consumers), in addition to a "standard auction" (where bidders compete on how much they pay to the government). The effects of an incumbent bidder are different with standard and price auction.

In a "standard auction", for given (expectations of) demand and costs functions, the incumbent is willing to pay more than a new bidder: if it wins, it has a monopoly on the two facilities; if it loses, there is a duopoly. With private-values, the incumbent is bids more aggressively and wins more often. However, the incumbent's expected surplus (i.e. total profit

\footnotetext{
${ }^{1}$ This process is also referred to as "franchising" instead of tendering,

${ }^{2}$ Cases related to the bidding with an incumbent include takeover battles with some bidders owning part of the target (Burkart, 1995; Bulow et al., 1999); and tender auctions when a firm is advantaged by having information on potential customers or a well-known brand-name (Klemperer, 1998). Other cases are: dissolution of partnerships (Cramton et al., 1987), creditors bidding in bankruptcy auctions (Burkart, 1995), heirs bidding for a family estate (Engelbrecht-Wiggans, 1994), and charity auctions (Goeree et al., 2005). In all these settings, some or all bidders receive a share of (the utility from) the winning offer. Also in procurement auction, advantages can be important. McAfee and McMillan (1989) study procurement when there are two types of bidders, domestic and foreign, who differ in the distribution that they draw their values from. It may be optimal for the government to discriminate between types — and hence not necessarily buy from the cheapest firm — because this intensifies the competition in the auction.

${ }^{3}$ An ascending auction, where the winner has to match the offer at which the last loser dropped out, seems realistic in many setting. Note that with two bidders, the ascending and sealed-bid versions of the second-offer auction are equivalent, so this distinction can be ignored. The related study on tender auctions by Krishna and Rosenthal (1996) used second-offer "standard auctions". As they argue: if reality is best described by a true first-offer setting, than our second-offer modeling can be seen as an approximation.

${ }^{4}$ Firms could alternatively differ on (the expectance on) the demand function. The results of this paper would generally hold (see Section 6 for a discussion).
} 
minus payment) will tend to be lower than the expected surplus, with two new bidders, of a bidder plus that on the initial facility that is not auctioned; the incumbent's surplus may be higher when the new bidder can never win the auction or refuses to enter due to bidding costs. The new bidder always loses if there is little heterogeneity or if the facilities are strong substitutes/complements. All this can severely limit — or even eliminate - the competition for the field, and especially in a (network) market with many interconnected facilities such as public transport or airports.

These results are in broad accordance with the literature. Krishna and Rosenthal (1996) study radio-frequency auctions (using standard "second-offer" auctions) for multiple regions with local and global bidders, where the latter gain synergies if they win in multiple regions and thus bid higher for given values for the frequency in a region. Burkart (1995) and Singh (1998) investigate a takeover battle of a firm where one bidder owns part of it (i.e. has a toehold) and the second does not. They use a second-price auction and private-values. The toehold bidder bids more aggressively and bids above its valuation of the firm, which is compensated by the fact that if it loses it gains a higher payment for its toehold shares. Different from my setting, the toehold bidder's expected surplus is higher than without a toehold. The toehold also raises the expected revenue for the other shareholders, but leaves the other bidder worse off. My definition of incumbents differs from Laffont and Tirole (1993)'s, where the incumbent currently has the procurement/tender contract, but the contract is reauctioned. If investments are non-transferable and sunk, the incumbent is more likely to win the reauction.

A "standard auction" only raises revenue. As Hazlett and Muñoz (2009) also argue, a welfare-maximising government should also care about consumer surplus and fostering competition. This could be done by attracting more firms to the market or direct regulation. Alternatively, the government could endogenously regulate via an auction on the price that will be set. ${ }^{5}$ The advantage of this over direct regulation is that the government needs less (or even no) information on the demand and cost conditions. With a perfectly-competitive auction, a price auction leads to the first-best outcome of marginal-cost pricing; while a standard auction never attains the first-best (Verhoef, 2007). ${ }^{6}$ With imperfect competition, a price auction generally does not result in marginal-cost pricing; but the price does approach the winner's marginal cost as the auction becomes more competitive.

A price auction is also affected if there is an incumbent. This paper finds that it depends which bidder is more likely to win: with substitutes, the incumbent bids a higher price (for given signals) and is thus less likely to win; with complements, the converse holds. Under private-values, a new firm offers a price equal to its marginal cost. With complements, the incumbent is willing to offer a price below its marginal cost, as this is compensated by that,

\footnotetext{
${ }^{5}$ Alternatively, they could compete on the number of users, which is equivalent in our setting (see also Verhoef, 2007).

${ }^{6}$ Perfect competition seems unlikely in an auction: in reality, costs and demands do vary over firms (Gómez-Ibáñez and Meyer, 1993) and there seems to be substantial uncertainty (Flyvbjerg et al., 2003, 2007). Moreover, there are often a limited number of bidders.
} 
when it loses, the new firm will have to set a lower price, and this raises the profit from the other facility. Conversely, with substitutes, the incumbent wants a higher price on the new facility to increase the profit from the other one.

In auctions on the number of users or service quality similar considerations come to play, and it also depends who is advantaged. An auction on service quality (with regulated price) is for example used in tendering public transport in the Netherlands (Mouwen and Rietveld, 2012), and government procurement often uses auctions where bids are scored on purchase price and quality (Che, 1993; Asker and Cantillon, 2010).

The common-values setting gives a more extreme outcome than private-values. Now, this paper finds that the bidder who has the advantage always wins - even if it has the lowest signal and the other the highest - and for any parameterisation. The incumbent always wins the standard auction and the price auction with complements, and always loses the price auction with substitutes.

Klemperer (1998) studies common-values where one bidder has a tiny extra value. He also finds that the advantaged bidder always wins. Bulow et al. (1999) extend this to a takeover battle with common-values and both bidders having a toehold. The bidder with the larger toehold is advantaged, but does not always win. They also study a first-price auction, and find that it often improves the outcome for the auctioneer.

\section{General set-up}

The two facilities are imperfect substitutes or complements. Facility $A$ is auctioned off; the incumbent owns facility $B$. The number of users of $A$ is $q_{A}$; its price is $p_{A}$; and demand and inverse demands for $A$, respectively, follow (and likewise for $B$ ): ${ }^{7}$

$$
\begin{aligned}
& q_{A}=b_{0}-b_{1} \cdot p_{A}+b_{2} \cdot p_{B}, \\
& p_{A}=d_{0}-d_{1} \cdot q_{A}+d_{2} \cdot q_{B} .
\end{aligned}
$$

Demand decreases with the own price, and hence $d_{1}, b_{1}>0$. For substitutes, demand increases with the other's price, and thus $b_{2}>0$ and $d_{2}<0$; the opposite holds for complements. Assuming away income effects, consumer surplus is the line-integral of the two demands. Welfare is the sum of consumer surplus and profits (including payment to the government), and thus the value of a dollar of revenue for the government is assumed to be one dollar and taxation is costless.

In the duopoly, firms maximise their profit given the other's price. Because the facilities are not perfect substitutes, the firms make a profit even though they compete on prices. The marginal cost of $A$ for bidder $k$ is $m c_{k, A}$. On $B$, marginal cost is $m c_{B}$. The price of firm $k$ on facility $A$, for a given price on $B$, can be shown to be (and similarly for $B$ )

\footnotetext{
${ }^{7}$ Here, $b_{0}=d_{0} /\left(d_{1}+d_{2}\right)>0, b_{1}=d_{1} /\left(d_{1} \cdot d_{1}-d_{2} \cdot d_{2}\right)>0$ and $b_{2}=-d_{2} /\left(d_{1} \cdot d_{1}-d_{2} \cdot d_{2}\right)$, and following standard micro $d_{1} \cdot d_{1}>d_{2} \cdot d_{2}$ (Mas-Colell et al., 1995).
} 


$$
p_{k, A}^{*}=\frac{d_{0}+d_{2} p_{B}+d_{1} \cdot m c_{k, A}}{2 d_{1}},
$$

Where superscript ${ }^{*}$ indicates the duopoly, and ${ }^{* *}$ will indicate a monopoly. The Nashequilibrium prices, and thus profits, are easily obtained from this equation.

If the incumbent controls $A$ and $B$, we have a monopoly, and the price equation is

$$
p_{I, A}=\frac{d_{0}+d_{2} p_{B}+d_{1} \cdot m c_{I, A}+d_{2}\left(p_{B}-m c_{B}\right)}{2 d_{1}}
$$

With substitutes $b_{2}>0$, and hence the monopolistic prices are higher than the duopolistic ones. Conversely, with complements $b_{2}<0$, and a duopoly leads to even higher prices than a monopoly (see also Economides and Salop, 1992), as a duopolistic firm ignores that its markups lower the profit of the other. The incumbent increases its profits from $B$ if it wins $A$; except with independent markets $\left(b_{2}=0\right)$ or when the price of $A$ is forced to equal the marginal cost (due to regulation or an auction), when the profit of $B$ is unaffected. Under the duopoly, the equilibrium prices are higher, the higher the cross-price parameter $b_{2}$ is.

The signal of both bidders is drawn from the same distribution that ranges between zero and one. The distribution function is $F[t]$, the density function $f[t] \equiv \partial F[t] / \partial t$. This paper considers common- and private-value settings. With private-values, the marginal cost on $A$ decreases with the bidders signal, $t_{k}$, following

$$
m c_{A, k}^{p}\left[t_{k}\right]=m c_{\max }^{p}-r \cdot t_{k}
$$

where superscript ${ }^{p}$ indicates private-values, $m c_{\max }^{p}$ is the maximum marginal cost with privatevalues, and $r$ a positive parameter. Similarly, with common-values, the marginal cost linearly decreases in the signals of bidders $k$ and $j$ :

$$
m c_{A, k}^{c}\left[t_{k}+t_{j}\right]=m c_{\max }^{c}-\frac{r}{2}\left(t_{k}+t_{j}\right)
$$

where superscript ${ }^{c}$ indicates common-values. The paper considers second-offer auctions, where the winner should at least match the loser's offer. When a tie occurs, the winner is determined by a coin flip.

\section{Bidding without an incumbent bidder}

To understand the effects of an incumbent bidder owning a complement or substitute to the facility that is tendered, one first needs to understand the outcome without them. Hence, this section analyses two new bidders competing for $A$, whereas the incumbent owns $B$ and sets the 
duopolistic price following (0). ${ }^{8}$ In general, with a second-offer auction without an incumbent, a bidder offers its value (Burkart, 1995; Klemperer, 1998), and at that offer makes a zero profit.

We will start with the symmetric bidding strategies with common-values; those with private values will follow naturally from these. In a standard auction, the duopolistic profit from $A$ for bidder $k\left(\Pi_{A}^{*}\left[t_{k}, t_{j}\right]\right)$ increases in both signals. Assuming that the bidding strategies are the same for the two, it is optimal for $k$ to offer to transfer (i.e. pay or receive) its entire profit when $t_{j}=t_{k}$ :

$$
T_{k}^{c}\left[t_{k}\right]=\Pi_{A}^{*}\left[t_{k}, t_{k}\right]
$$

where superscript ${ }^{c}$ indicates common-values, and ${ }^{*}$ a duopolistic market. Suppose $k$ offered a slightly higher transfer instead: nothing changes if it won before and still wins (it still pays $j$ 's offer) or if $k$ still loses (it still has zero profit); but, if $k$ lost before and now wins, the payment must be higher than the profit, and $k$ attains a negative pay-off. Symmetrically, if $k$ would bid lower, it would be worse off if it just won the auction before, and now loses it.

Similarly, with a price auction, $k$ offers a price equal to marginal cost when $t_{j}=t_{k}$, such that it then makes a zero profit:

$$
p_{A, k}^{c}=m c_{A, k}^{c}\left[t_{k}+t_{k}\right]=m c_{\max }^{c}-\frac{r}{2}\left(t_{k}+t_{k}\right)=m c_{\max }^{c}-r \cdot t_{k} .
$$

Offering a lower price might lead $k$ to win the auction if $j$ 's signal is slightly higher than $k$ 's, and then $k$ would have to set its price below marginal cost. Hence, this is also not profitable.

With private values, the optimal offers can be found in a similar fashion:

$$
\begin{aligned}
& T_{k}^{p}\left[t_{k}\right]=\Pi_{A}^{*}\left[m c_{A, k}^{p}\left[t_{k}\right]\right], \\
& p_{A, k}^{p}=m c_{A, k}^{p}\left[t_{k}\right]=m c_{\text {max }}^{p}-r \cdot t_{k} .
\end{aligned}
$$

From these equations it is simple to calculate the expected payment to the government or price, as well as the expected profits and consumer surplus.

\subsection{Numerical example}

Now the set-up of the numerical example is introduced, which is also used in the following sections. It is important to look at an example: the analytics can show that having an incumbent matters, but the question that remains is how much? Table 1 introduces the parameterisation. There are two cases: in the first the facilities are substitutes, in the second complements. The marginal cost on $B$ equals 5 . On $A$, the marginal cost has a range of 2 ; and, with two new bidders, the mean of the winner's marginal cost is 5 . The signals are IID and uniformly distributed between zero and one: for $0 \leq t \leq 1$, the distribution function of signal $t$ is $F[t]=t$, and the density $f[t]=1$.

\footnotetext{
${ }^{8}$ It is assumed that the firms compete Nash, even though with a price auction it is conceivable that the winner is a price-leader, as its price is constrained by the auction. This would then give a new bidder an extra disadvantage under substitutes and an advantage under complements (see Gal-Or, 1985). This would, hence, be a second source of advantages, but would also complicate the analysis.
} 
Table 1: Parameterisation of the example

\begin{tabular}{lc}
\hline Parameter & Value \\
\hline$d_{0}$ & $115 / 5$ \\
$d_{l}$ & $-4 / 15$ \\
$d_{2}$ & $-1 / 15$ (substitutes) or $1 / 15$ (complements) \\
$r$ & 2 \\
$m c_{\max }^{p}$ & $6+1 / 3$ \\
$m c_{\max }^{c}$ & 6 \\
$m c_{b}$ & 5 \\
\hline
\end{tabular}

Table 2 tabulates the expected outcomes ( $\mathrm{E}[x]$ gives the expectation of $x$ ) under privatevalues; Table 3 does this for common-values. The calibration results in very similar outcomes under private- and common-values; which will help signify differences in the effects of an incumbent in the two settings. Since the strategies are symmetric, the results are given for any bidder $i$.

Table 2: Expected outcome under private-values and two new bidders

\begin{tabular}{|c|c|c|c|c|}
\hline & \multicolumn{2}{|c|}{ Substitutes $\left(d_{2}=-1 / 15 \approx-0.067\right)$} & \multicolumn{2}{|c|}{ Complements $\left(d_{2}=1 / 15 \approx 0.067\right)$} \\
\hline & Standard auction & Price Auction & Standard auction & Price Auction \\
\hline $\mathrm{E}[$ Price of $A]$ & 19.29 & 5.67 & 23.52 & 5.67 \\
\hline $\mathrm{E}[$ Price of $B]$ & 19.31 & 17.58 & 23.50 & 25.75 \\
\hline Prob. $i$ wins & 0.5 & 0.5 & 0.5 & 0.5 \\
\hline E[Consumer Surplus] & 1088.5 & 2317.9 & 1097.5 & 2862.4 \\
\hline $\mathrm{E}[$ Transfer by $i]$ & 389.7 & 0 & 661.9 & 0 \\
\hline $\mathrm{E}[$ Profit for $i$ from $A]$ & 408.27 & 36.42 & 685.98 & 47.53 \\
\hline $\mathrm{E}[$ Profit from $B]$ & 816.3 & 633.4 & 1371.8 & 1722.3 \\
\hline $\mathrm{E}[$ Welfare $]$ & 2721.4 & 3024.2 & 3841.2 & 4679.7 \\
\hline Relative efficiency $^{*}$ & 0.654 & 0.825 & 0.571 & 0.781 \\
\hline
\end{tabular}

Note: * relative efficiency of a policy equals the welfare gain from the base case (when there is no supply on $A$, and $B$ has a monopolistic price) divided by the gain from going to first-best marginal-cost pricing on $A$ and $B$.

Table 3: Expected outcome under common-values and two new bidders

\begin{tabular}{lc|c|c|c}
\hline & \multicolumn{2}{c|}{ Substitutes $\left(d_{2}=-1 / 15 \approx-0.067\right)$} & \multicolumn{2}{c}{ Complements $\left(d_{2}=1 / 15 \approx 0.067\right)$} \\
& Standard auction & Price Auction & Standard auction & Price Auction \\
\hline E[Price of $A]$ & 19.29 & 5.33 & 23.52 & 5.33 \\
E[Price of $B]$ & 19.29 & 17.54 & 23.52 & 25.79 \\
Prob. $i$ wins & 0.5 & 0.5 & 0.5 & 0.5 \\
E[Consumer Surplus] & 1088.5 & 2356.9 & 1097.5 & 2906.9 \\
E[Transfer by $i$ ] & 399.0 & 0 & 673.9 & 0 \\
E[Profit for $i$ from $A]$ & 408.08 & 18.43 & 685.79 & 23.98 \\
E[Profit from $B]$ & 816.3 & 629.2 & 1371.7 & 1729.2 \\
E[Welfare] & 2721.0 & 3022.9 & 3840.8 & 4684.0 \\
Relative efficiency & 0.654 & 0.825 & 0.571 & 0.782 \\
\hline
\end{tabular}

In the tables, the relative efficiency of a policy is the welfare gain from the base case (when there is no supply of $A$, and $B$ has a monopolistic price) relative to the gain from going to firstbest marginal-cost pricing. Looking at absolute values can be misleading. For instance, the auctions attain a higher welfare under complements than under substitutes, but this is because 
consumer surplus increases in $d_{2}$ (for given number of users). Actually, relative to the firstbest, the auctions fare worse under complements. A further advantage is that the relative measure indicates how important welfare differences are: if one policy has a $10 \%$ higher welfare, this is more impressive if the first-best has an $11 \%$ higher welfare than with a $100 \%$.

\section{Private-values auctions with an incumbent}

Now we turn to the case with an incumbent bidder. The new bidder bids just as before: in the standard auction, it offers to transfer the entire profit it would make to the government; in the consumer-price auction, it offers to set the price at its marginal cost. In the price auction, with substitutes, the incumbent is at the disadvantage: it offers a price that leads to profit on $A$, because, if it loses, this increases the new firm's price on $A$ and thereby the profit on $B$. Conversely, with complements, the incumbent offers a price that would lead to loss from $A$. With a standard auction, the situation is less complex. Given the signals, the incumbent just has a higher value: if it wins, it is a monopolist; when it loses, a duopolist.

\subsection{Standard auction and the incumbent}

The incumbent knows the bidding strategy on the new firm. We will use superscript I to indicate the incumbent. With a standard auction, it chooses a $t_{N}$ to emulate (which will be referred to as $t$ ) that maximises its expected pay-off, and therewith it chooses its transfer offer. The objective function is

$$
O_{I}=\left(\Pi_{A}^{* *}\left[t_{I}\right]+\Pi_{B}^{* *}\left[t_{I}\right]\right) F[t]-\int_{0}^{t} T_{N}[x] \cdot f[x] d x+\int_{t}^{1} \Pi_{B}^{*}[x] \cdot f[x] d x
$$

where the first term is the expected monopolistic profit from wining the auction, the second is the expected transfer paid (i.e. the expected second-highest offer conditional on the incumbent winning and thus $t \geq t_{N}$ ), and the third term is the expected duopolistic profit from $B$ when losing. Superscript ${ }^{* *}$ indicates a monopoly, and ${ }^{*}$ a duopoly. Differentiating (0) to $t$ gives

$$
\frac{\partial O_{I}}{\partial t}=0=\left(\Pi_{A}^{* *}\left[t_{I}\right]+\Pi_{B}^{* *}\left[t_{I}\right]-\Pi_{B}^{*}[t]\right) f[t]-T_{N}[t] \cdot f[t]
$$

where the term between brackets gives the profit gain from being a monopolist instead of a duopolist. This profit gain is larger than the profit a new bidder would make; therefore, the incumbent offers a higher transfer (i.e. payment to the government), and emulates a $t_{N}$ that is above its own signal. That is unless we have two independent markets, when the two profits would be equal, and thus having an incumbent has no effect.

This raises the question what the bidding will be when the incumbent always wins. If $t_{I}$ is really high, the new bidder can never out bid the incumbent, and $f[t]$ in (0) will be zero. The incumbent could then offer any payment above $T_{N}[1]$ (the new bidder's offer when $t_{N}=1$ ). Figure 1 illustrates the bidding using the numerical example (as introduced in Section 3); the left panel does this for substitutes $\left(d_{2} \approx-0.067\right)$, and the right for complements $\left(d_{2} \approx 0.067\right)$. In 
the Figure, with substitutes, the incumbent always wins if $t_{l}>0.66$; and it is assumed that the incumbent still offers its profit gain (which is a weekly dominant strategy, but so is any bid above $T_{N}[1]$ ). The outcome is independent of the incumbent's choice here (as long as its offer is above $\left.T_{N}[1]\right)$, as the incumbent always wins and pays the new bidder's offer.

Conversely, the outcome does depend on what happens when $t_{N}$ is so low that the new firm never wins (e.g. in Figure 1 for substitutes, when $t_{N}<0.35$ ), as then the new firm's bid determines what the incumbent will transfer. The example assumes that the new bidder still offers its profit, which is a weekly dominant strategy. If the new bidder followed a different strategy (or did not enter due to bidding costs) the expected transfer would differ, whereas welfare is unaffected if the value of revenue for the government is one.

Figure 1: Offered transfer with substitutes (left) and complements (right)in the numerical example
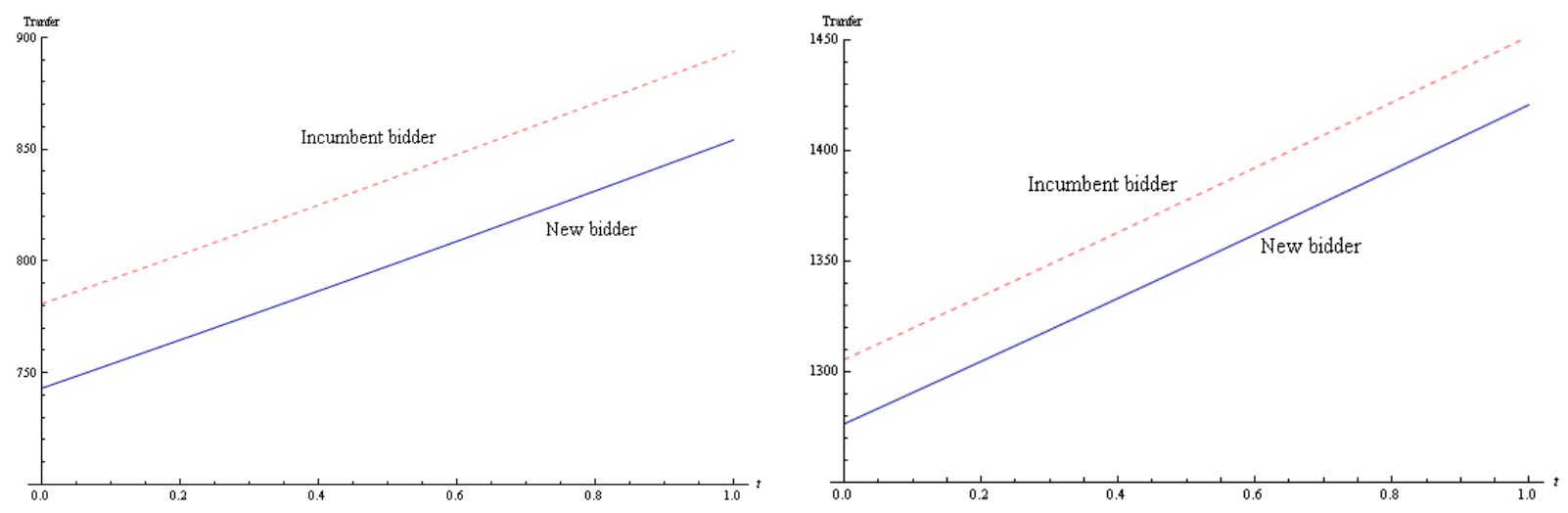

The auction is not always efficient, and the expected cost increases if the incumbent becomes more likely to win. With complements, a duopoly's prices are higher than a monopoly's. Consequently, with an incumbent bidder, the expected mark-ups are lower than with two new bidders, and this increases welfare.

There is also the issue of ex-post incentives to renege or renegotiate the contract, in that the incumbent will make a loss on its new facility if it only just wins the auction. Then, the firm may argue that it cannot be expected to keep its promise as it is making a large loss. Such tender contract renegotiation is, as Engel et al. (2001), very common. This paper assumes that such reneging or renegotiating is not possible.

\subsection{Price offer of the incumbent}

The objective function for the incumbent with a price auction is similar as before. The incumbent chose a $t_{N}$ to emulate; i.e. it chooses a $t$ that maximises

$$
O_{I}=\int_{0}^{t}\left(\Pi_{A}^{* *}\left[t_{I}, p_{A, N}^{p}[x]\right]+\Pi_{B}^{* * *}\left[t_{I}, p_{A, N}^{p}[x]\right]\right) \cdot f[x] d x+\int_{t}^{1} \Pi_{B}^{*}\left[p_{A, N}^{p}[t]\right] \cdot f[x] d x
$$

where the first integral gives the expected profit from winning $A$, and the second from losing. The $p_{A, N}^{p}[t]$ is the price the new firm offers when its signal is $t$. The profits when winning depend on the incumbent's signal $\left(t_{I}\right)$ —as this determines the marginal cost from (0) — and the 
loser's signal — as this determines the price. The profit on $B$ when losing $\left(\Pi_{A}^{*}\right)$ only depends on the price incumbent offered and thus on $t$.

The f.o.c. of the incumbent's choice is

$$
\frac{\partial O_{I}}{\partial t}=0=\left(\Pi_{A}^{* *}\left[t_{I}, p_{A, N}^{p}[t]\right]+\Pi_{B}^{* *}\left[t_{I}, p_{A, N}^{p}[t]\right]-\Pi_{B}^{*}\left[p_{A, N}^{p}[t]\right]\right) f[t]+(1-F[t]) \frac{\partial \Pi_{B}^{*}}{\partial p_{A}} \frac{\partial p_{A, N}^{p}[t]}{\partial t}
$$

where the term between brackets gives the profit gain from winning $A$ when the new bidder has a signal $t$. The second term is for when the new bidder wins, and gives the increase in profit from $B$ due to a marginal increase in $t$. Condition (0) implicitly defines the optimal offer. Given the linear nature of the model, it is possible to analytically solve it; but this solution is long and not insightful. For strong substitutes, the solution can even be an imaginary number, and hence then no real solution exists.

To help explain this setting, Figure 2 illustrates bidding using the numerical example. As noted, with substitutes, the incumbent is less likely to win, as, for given signals, it offers a higher price; with complements, the incumbent is more likely to win.

Figure 2: Offered price with substitutes (left) and complements (right)
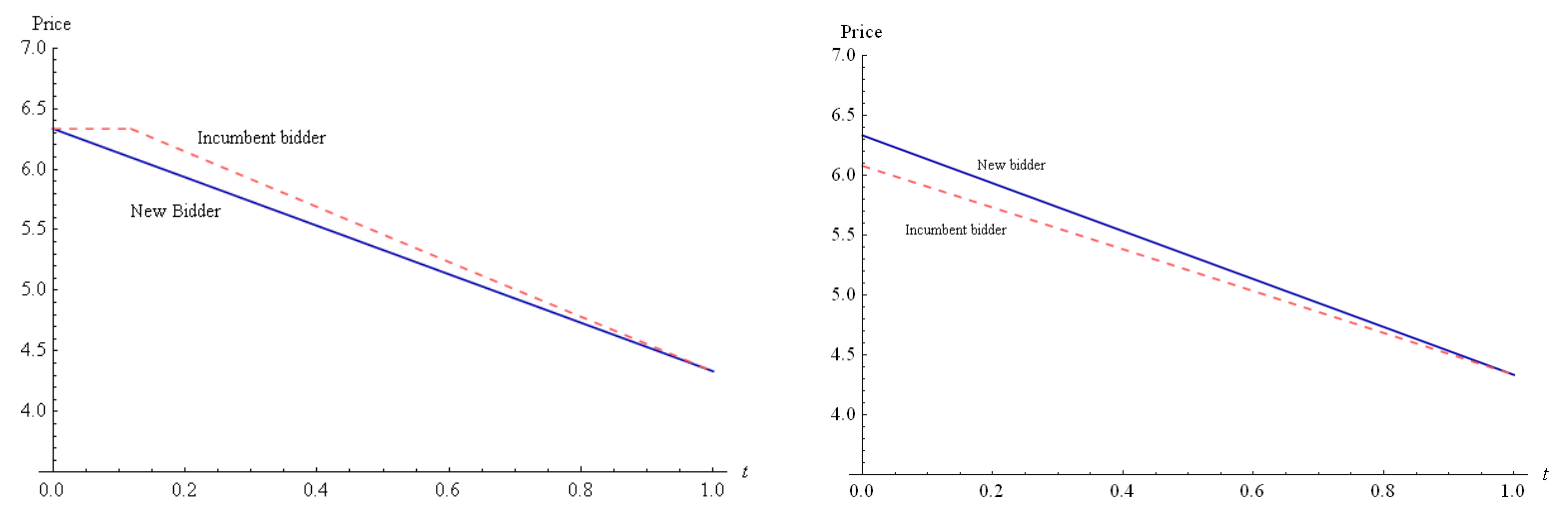

Returning to the analytics, assuming that a solution exists, with complements and given signals, the incumbent sets a lower price than the new firm: $t>t_{I}$. To prove this, we start with the situation $t=t_{I}$. Then, the first term of (0) equals zero, ${ }^{9}$ whereas the second term is positive if $t_{I}<1 .^{10}$ To equate the f.o.c. of ( 0 ) to zero, the $t$ has to increase. ${ }^{11}$ The exception is at $t_{I}=1$, as then the second term in $(0)$ is zero as $1-F[t]=0$, and thus the incumbent gives the same offer as the new bidder would: $p_{A, N}^{p}[1]=p_{A, I}^{p}[1]$.

\footnotetext{
${ }^{9} \Pi_{A}^{* *}\left[t_{I}, p_{A, N}^{p}\left[t=t_{I}\right]\right]=0$, as the incumbent would offer a price equal to its marginal cost; and $\Pi_{B}^{* * *}\left[t_{I}, p_{A, N}^{p}\left[t=t_{I}\right]\right]=\Pi_{B}^{*}\left[p_{A, N}^{p}\left[t=t_{I}\right]\right]$ : the profit from $A$ is always zero, and thus it is always optimal for the price on $B$ to maximise the profit from $B$.

${ }^{10}$ Then $1-F[t]>0$, whereas the other two terms are negative: the profit from $B$ decreases in $A$ 's price with complements ( $\left.\partial \Pi_{B}^{*} / \partial p_{A}<0\right)$, and the price offer of the new bidder decreases in its signal $\left(\partial p_{A, N}^{p}[t] / \partial t<0\right)$.

${ }^{11}$ This makes the first term in (0) negative and the second term less positive (because $1-F[t]$ becomes smaller and $\partial \Pi_{B}^{*} / \partial p_{A}$ less negative).
} 
Symmetrically, with substitutes, the $t$ should be smaller than $t_{I}$. At $t=t_{I}$, the first term of $(0)$ is zero and the second is negative, because, with substitutes, the profit from $B$ increases with the price of $A$ instead of decreases as happens with complements.

For the price auction to work, the government has to set a maximum price. Otherwise the incumbent is typically better off by bidding the unregulated duopolistic price (or higher) instead of following (0). Thereby, it loses the auction, but gains a much better outcome for $B$, which often raises its total profit. Hence, the government has to ensure that the incumbent bids seriously. An obvious candidate for this maximum is the highest possible marginal cost, and this is also used in the example (in the example of Figure 2 this explains the horizontal section of the dashed bidding curve, as there the constraint is binding).

A slightly higher maximum price has no effect with complements, but with substitutes it does. With substitutes, for the range of $t_{I}$ where the incumbent can never win (i.e. from zero to the critical value), the best it can do is offer the highest possible price. A higher reserve would thus lower welfare. But the loss might not be that large: in the numerical example, when we compare the reserve $p_{A} \leq m c_{m a c}$ with the case where the incumbent can set the duopolistic price when $t_{I}$ is below the critical value (but not when it is above it), the latter has a welfare that is $1 \%$ lower. The welfare from a realistic reserve (which ensures that the incumbent bids seriously) is in between these two cases; and thus the loss from a higher maximum might be limited. Still, the loss is larger when the range for with incumbent never wins is larger: e.g. a more negative $d_{2}$ or less heterogeneity in the marginal cost.

\subsection{Numerical example}

We now continue with the numerical example. As discussed, Figure 1 gives the example transfer offers, and 2 the price offers. Table 4 discusses the expected effects of the auctions averaged over all possible signals.

Table 4: Expected outcome under private-values

\begin{tabular}{|c|c|c|c|c|}
\hline & \multicolumn{2}{|c|}{ Substitutes $\left(d_{2}=-1 / 15 \approx-0.067\right)$} & \multicolumn{2}{|c|}{ Complements $\left(d_{2}=1 / 15 \approx 0.067\right)$} \\
\hline & Standard auction & Price Auction & Standard auction & Price Auction \\
\hline $\mathrm{E}[$ Price of $A]$ & 20.10 & 5.74 & 21.77 & 5.59 \\
\hline $\mathrm{E}[$ Price of $B]$ & 20.03 & 17.64 & 21.74 & 25.72 \\
\hline Prob. $N$ wins & 0.21 & 0.56 & 0.31 & 0.44 \\
\hline $\mathrm{E}[$ Marginal cost of $A]$ & 5.039 & 5.004 & 5.091 & 5.005 \\
\hline $\mathrm{E}[$ Consumer Surplus] & 821.1 & 2307.0 & 1273.4 & 2876.3 \\
\hline $\mathrm{E}[$ Transfer by $N]$ & 178.0 & 0 & 431.7 & 0 \\
\hline $\mathrm{E}[$ Transfer by $E]$ & 620.0 & 0 & 913.0 & 0 \\
\hline $\mathrm{E}[\text { Profit for } N \text { from } A]^{\#}$ & 178.0 & 44.6 & 431.7 & 36.5 \\
\hline $\mathrm{E}[\text { Profit for } \mathrm{E} \text { from } A]^{\#}$ & 352.3 & 36.0 & 667.9 & 46.8 \\
\hline $\mathrm{E}[$ Profit from $B]$ & 830.5 & 634.3 & 1383.5 & 1723.9 \\
\hline E[Welfare] & 2476.1 & 3021.9 & 4040.4 & 4683.4 \\
\hline Relative efficiency $^{*}$ & 0.516 & 0.824 & 0.621 & 0.782 \\
\hline
\end{tabular}

Note: * relative efficiency of a policy is the welfare gain from the base case (when there is no supply on $A$, and $B$ has a monopolistic price) divided by the gain from going to first-best pricing on $A$ and $B .{ }^{\#}$ The profit includes the transfer that will be given to the government. 
In the standard auction, the incumbent offers a higher transfer for a given signal, as when it wins it is a monopolist instead of a duopolist. The incumbent wins more often, but it expects to pay a higher transfer than the profit from $A$ : its expected surplus (i.e. profit minus payment) is lower than, with two new bidders, the expected surplus of a bidder plus the profits of the facility that is not auctioned. Moreover, this always holds unless the new bidder can never win, which as we will see occurs if the facilities are very strong complements or substitutes or if the is little heterogeneity. The new bidder also loses due to the incumbent. The government tends to gain from the slightly higher transfer, but with substitutes welfare is lower as the incumbent is more often a monopolist.

The price auction leads to a higher welfare than the standard auction: it leads to lower expected prices and also to a slightly lower expected marginal cost. Under substitutes, even the price auction without a reserve does better than the standard auction: it always leads to an unregulated duopoly, whereas the standard auction leads to a monopoly $79 \%$ of the time. The price auction is also less affected by an incumbent bidder: for the price auction welfare is only slightly higher with two new bidders, whereas with the standard auction the effect can be large. However, with a standard auction under complements, the incumbent bidder case has a higher welfare, as it more often leads to a monopoly instead of a more harmful duopoly.

\subsection{Sensitivity analysis}

This section briefly investigates how sensitive the results are to the parameterisation. It will focus on the effect of the cross-price sensitivity $\left(d_{2}\right)$. The effects of other parameters are as one would expect: for instance, a stronger sensitivity to the own-price decreases market power, and hence private supply fares better and there is less to gain from a price auction. The effect of the amount of heterogeneity in the marginal cost is also important. Less heterogeneity means that an advantaged bidder - defined as the one that is more likely to win — wins even more often, as the signal difference in favour of the disadvantaged needs to be even larger for it to win. For a low amount of heterogeneity, the disadvantaged bidder can never win.

As Figure 3 shows, when the facilities are stronger substitutes (more negative $d_{2}$ ) or stronger complements (more positive $d_{2}$ ), the chance that the new bidder wins a standard auction decreases, as this increases the profit gain for facility $B$ from being a monopolist. Indeed, for independent markets, the incumbent is just a regular bidder; for strong substitutes $\left(d_{2}<-0.1\right)$ or complements $\left(d_{2}>0.19\right)$, the incumbent always wins. For substitutes, the relative efficiency increases with $d_{2}$, as the chance that there will be a duopoly increases. For complements, the relative efficiency also tends to increase with $d_{2}$, because the chance of a duopoly decreases.

Figure 4 displays the effect of $d_{2}$ on the price auction and in particular on the chance that the new bidder wins and the relative efficiency. As discussed, with substitutes the new bidder wins more often. This harms the incumbent, but increases welfare by lowering the expected price. 
Figure 3: Sensitivity of the outcome of the standard auction to the cross-price sensitivity $\left(d_{2}\right)$
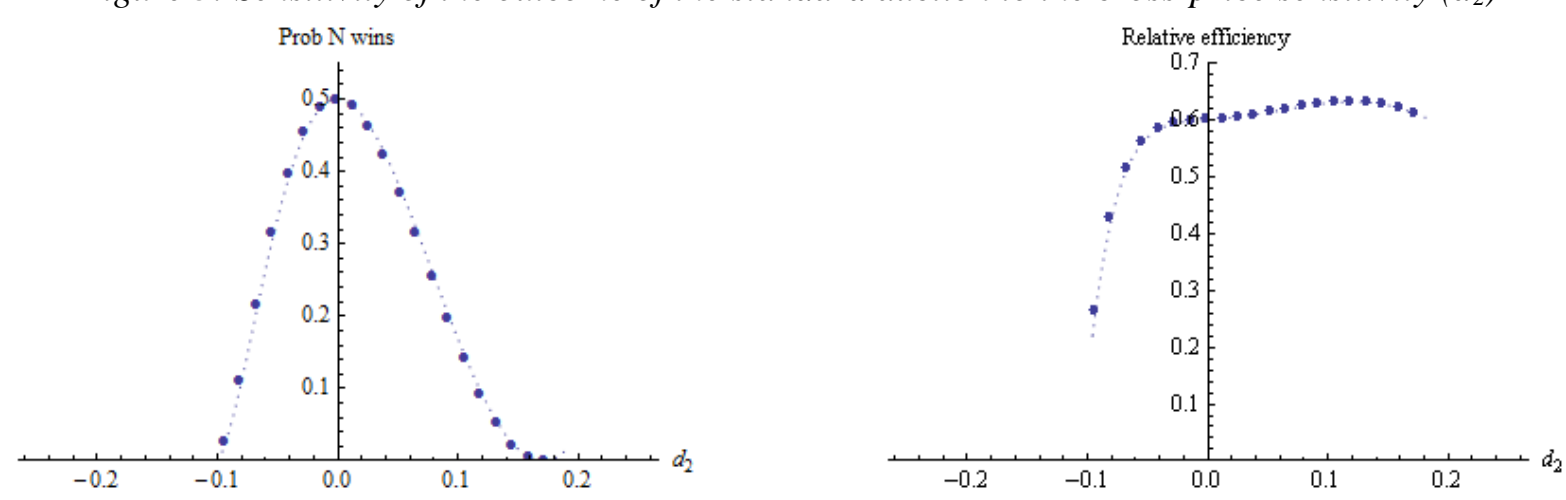

Figure 4: Sensitivity of the outcome of the price auction to the cross-price sensitivity $\left(d_{2}\right)$
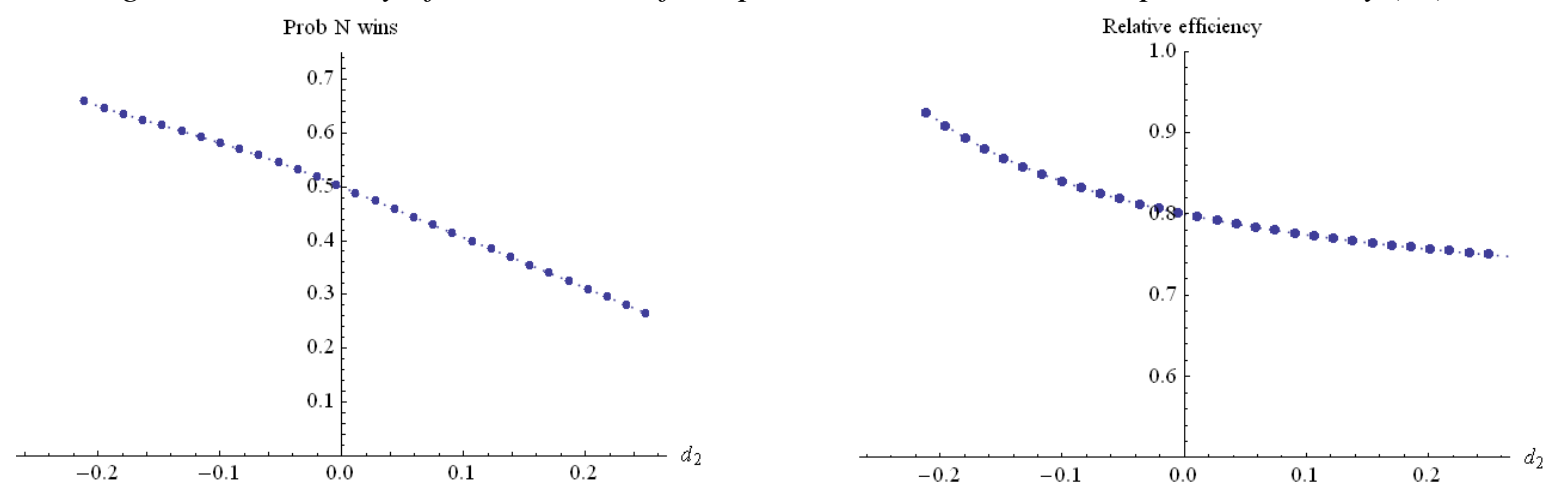

\section{Common-values auctions with an incumbent}

With common-values, the bidder who has the advantage always wins. This result can be illustrated by the case where the value of winning is just the sum of the two signals, but the advantaged firm has a tiny extra value $\alpha>0$. The disadvantaged firm $d$ with signal $t_{d}$ is willing to pay $t_{a}+t_{d}$ (note that it does not know $t_{a}$, but it does have a belief about it), whereas the other is willing to pay $t_{a}+t_{d}+\alpha$. Suppose the disadvantaged followed the same strategy as without advantages, and bids twice its signal: $t_{d}+t_{d}$. If it would then win, this would be very bad news: then the advantaged signal must follow $t_{a} \leq t_{d}-\alpha / 2$, and thus the value for the disadvantaged is not above $t_{a}+t_{d}-\alpha / 2$, which is below the bid. Hence, whenever it wins, it makes a loss. To overcome this, the disadvantaged shades its bid. But knowing this, the advantaged can bid more aggressively, which in turn implies that the disadvantaged must shade its bid even more, and so on until the disadvantaged always bids as if the advantaged's signal is zero (or does not bid at all if, for example, there are bidding costs). Hence, the disadvantaged never wins, and the advantaged wins at a low payment (i.e. transfer).

In a standard auction, the incumbent always wins: for given signals, the new bidder can offer the duopolistic profit from $A$, the incumbent offers the expected maximum profit gain due to being a monopolist on $A$ and $B$ instead of a duopolist on $B$. The incumbent can offer the higher transfer unless the demands are independent, and there are thus just two standard 
bidders. In a price auction, the advantage depends. With complements and given signals, the incumbent offers a lower price and thus always wins; with substitutes, it offers a higher price and always loses.

\subsection{Numerical example}

We now turn to the numerical example. The results in Table 5 should be compared to those in Table 3 for two new bidders. Having a bidder that always wins needs not be bad: now, with complements, a standard auction leads to an unregulated monopoly, whereas, in Table 3 , the more harmful duopoly occurs $50 \%$ of the time. Conversely, with substitutes, the standard auction works badly: it attains less revenue and ensures a monopoly.

The results assume that the new bidder still bids its value and thus offers the profit it would make under $t_{I}=0$. This may not be realistic, as the new bidder has no chance of winning, and thus, if there are the tiniest bidding costs it would never enter the auction. Then, our results are more extreme: the same prices would be set, but the transfer would be zero.

Just as with private-values, in the price auction, the government imposes a maximum price equal to the highest possible marginal cost. It may not be able to set such a maximum, or the maximum may be higher. The worse possible outcome is when there is no maximum at all. Then, under substitutes, the outcomes of the price and standard auctions are the same: both make the incumbent the unregulated monopolist. Under complements, the price auction fares better; the incumbent has 2 choices: (1) win $A$, and own both facilities with tiny profit on $A$ and a large one on $B$, or (2) be a duopolist and get a medium profit from $B$, as the new firm will set a Nash-equilibrium price that is above the monopolistic one. The incumbent will tend to be better off the former case, which also has the higher welfare. ${ }^{12}$

Table 5: Expected outcome under common-values and no reserve

\begin{tabular}{lc|c|c|c}
\hline & \multicolumn{2}{c|}{ Substitutes $\left(d_{2}=-1 / 15\right)$} & \multicolumn{2}{c}{ Complements $\left(d_{2}=-1 / 15\right)$} \\
& Standard auction & Price Auction & Standard auction & Price Auction \\
\hline E[Price of $A$ ] & 21.67 & 6.00 & 21.67 & 5.50 \\
E[Price of $B]$ & 21.67 & 17.63 & 21.67 & 25.71 \\
Prob. $N$ wins & 0 & 1 & 0 & 0 \\
E[Consumer Surplus] & 833.42 & 2278.99 & 1388.97 & 2889.52 \\
E[Transfer by $N]$ & 0 & 0 & 0 & 0 \\
E[Transfer by $E]$ & 788.53 & 0 & 1335.62 & 0 \\
E[Profit for $N$ from $A]$ & 0 & 746.19 & 0 & 0 \\
E[Profit for $E$ from $A]$ & 833.50 & 0 & 1389.06 & 71.99 \\
E[Profit from $B]$ & 833.33 & 634.32 & 1388.89 & 1725.69 \\
E[Welfare] & 2500.25 & 3025.18 & 4166.92 & 4687.20 \\
Relative efficiency & 0.53 & 0.78 & 0.65 & 0.75 \\
\hline
\end{tabular}

\footnotetext{
${ }^{12}$ For the common-value, no sensitivity analysis will be presented as nothing interesting happens: the advantaged bidder always wins, and the main effect in the private-values sensitivity analysis was via the advantaged bidder's position.
} 


\section{Discussion}

Now we turn to some caveats to the research. The previous sections already discussed that the price auction needs a maximum price, and that it is important what a bidder does when it always loses. It was assumed that it bids its value. If it did not enter the auction, the standard auction would lead to a zero transfer, and the price auction to the unregulated outcome. The discussion of the welfare effects assumes that the marginal social cost of taxation is zero and thus the value of public funds is one. If the value is higher, the standard auction's revenue is more valuable and thus its welfare higher. With private-values and a standard auction, this could also make the presence of an incumbent bidder welfare improving, as this often increases expected transfer. ${ }^{13}$

Bidders are assumed to differ in (the expectation of) the marginal costs. They could also differ in the intercept of the demand function or the price sensitivity. The results with privatevalues would be qualitatively the same. However, if marginal costs are constant, the priceauction with common-values would be affected: all bidders would then always bid the fixed, and shared, marginal cost as the price, and thus there would be no advantages. If marginal costs are marginally non-linear, ${ }^{14}$ then there would be a bidder that always wins.

\section{Conclusion and policy implications}

This paper finds that having an incumbent bidder has substantial effects, and, in many settings, one bidder always wins, and does so at a low transfer in the standard auction and a high price in the regulatory price auction. The incumbent wins the "standard auction" more often. If there is little heterogeneity in the bidders' marginal costs or the facilities are strong substitutes/complements, the new bidder can never win. Conversely, with a "(consumer) price auction" under substitutes, the new bidder is more likely to win: for given signals, the incumbent sets a higher price as it also cares about the profit of the substitute. With a price auction and complements, the incumbent wins more often: it is willing to set a lower price, as this helps the other facility. With private values, the bidder who bids better for given signals wins more often; with common-values, she will always win and at low payment or high price, as the other bidder can never compete.

All this can have great consequences for the tendering in network markets-such as telecommunication. If a firm becomes an incumbent, it may win all future auctions, and at a low transfer or a high (consumer) price. This could hence severely limit the competition for the field. This is especially true for the "standard auction", whereas the "price auction" often gives smaller advantages and to new entrants in the case of substitutes. This is especially important if there are bidding costs, as then bidders with a small chance of winning would not enter the

\footnotetext{
${ }^{13}$ There is an extensive literature on the marginal cost of taxation that builds on Browning (1976). He found a marginal cost of 9 to $16 \%$ of revenue. Later studies often found higher costs: e.g., Kleven and Kreiner (2006) found values between $26 \%$ for the UK and $120 \%$ for Denmark.

${ }^{14}$ Or if there are congestion costs (usage costs increase with the number of users) or network effects (the value of consumption for a given user increases with the number of users).
} 
auction, further increasing the advantage of the incumbent and possibly leaving it as the only bidder.

A question that remains is: what can the government do to improve the outcome? An option would be a standard auction with price regulation. If the government imposes a price cap, the incumbent loses its advantage. Alternatively, a rate of return regulation could limit the profit gain from being an incumbent, and thus its effects. It could also help to impose stricter reserves or, following McAfee and McMillan (1989), differentiate between types of bidders to increase the competition. Following Goeree and Offerman (2004), another alternative to stiffen the auction competition is giving the loser of the auction part of auction revenue.

A final option, which has received interest in the takeovers literature, is giving the disadvantaged bidder a toehold at a discounted or zero price (e.g., Bulow et al., 1998; Rothkopf et al., 2003). Subsidising bidders is also an option in procurement (see, e.g., Cantillon, 2008). In the context of this paper, the government could offer a third facility only to non-incumbents. A further advantage of more and perhaps smaller facilities is that this fosters competition, and this can also raise welfare.

\section{Acknowledgements}

Financial support from the ERC (AdG Grant \#246969 OPTION) is gratefully acknowledged. I am grateful for the comments of Harry van der Weijde, Sergej Gubins, Paul Koster, Alex Dimitropoulos, Hugo Silva, Erik Verhoef and Eva Gutiérrez. I thank the participants of the Eureka seminar (13 September 2012, Amsterdam), and the NARSC conference (8 November 2012, Ottawa). The usual disclaimer applies.

\section{References}

Asker, J., Cantillon, E., 2010. Procurement when price and quality matter. RAND Journal of Economics 41(1), 134.

Browning, E.K., 1976. The marginal cost of public funds. Journal of Political Economy 84(2), 283-298.

Bulow, J., Huang, M., Klemperer, P., 1999. Toeholds and takeovers. Journal of Political Economy 107(3), 427454.

Burkart, M., 1995. Initial shareholdings and overbidding in takeover contests. Journal of Finance 50(5), 14911515.

Cantillon, E., 2008. The effect of bidders' asymmetries on expected revenue in auctions. Games and Economic Behavior 62(1), 1-25

Che, Y.-K., 1993. Design competition through multidimensional auctions. RAND Journal of Economics 24(4), 668-680.

Cramton, P., Gibbons, R., Klemperer, P., 1987. Dissolving a partnership efficiently. Econometrica 55(3), 615-32.

Economides, N., Salop, S.C., 1992. Competition and integration among complements, and network market structure. Journal of Industrial Economics 40(1), 105-123.

Engelbrecht-Wiggans, R., 1994. Auctions with price-proportional benefits to bidders. Games and Economic Behavior 6(3), 339-46.

Flyvbjerg, B., Holm, M.K.S., Buhl, S.L., 2003. How common and how large are cost overruns in transport infrastructure projects? Transport Reviews 23(1), 71-88.

Flyvbjerg, B., Holm, M.K.S., Buhl, S.L., 2006. Inaccuracy in traffic forecasts. Transport Reviews 26(1), 1-24.

Gal-Or, E., 1985. First mover and second mover advantages. International Economic Review 26(3), 649-653.

Goeree, J.K., Maasland, E., Onderstal, S., Turner, J.L., 2005. How (not) to raise money. Journal of Political Economy 113(4), 897-918.

Goeree, J.K., Offerman, T., 2004. Notes and comments the Amsterdam auction. Econometrica 72(1), 281-294.

Hazlett, T.W, Muñoz, R.E., 2009. A welfare analysis of spectrum allocation policies. RAND Journal of Economics 40(3), 424-454. 
Klemperer, P., 1998. Auctions with almost common values: the 'wallet game' and its applications. European Economic Review 42(3-5), 757-769.

Kleven, H.J., Kreiner, C.T., 2006. The marginal cost of public funds: hours of work versus labor force participation. Journal of Public Economics 90(10-11), 1955-1973.

Krishna, V., Rosenthal, R., 1996. Simultaneous auctions with synergies. Games and Economic Behavior 17(1), 131.

Laffont, J.J., Tirole, J., 1993. A Theory of Incentives in Procurement and Regulation. Cambridge: MIT Press.

Mas-Colell, A., Whinston, M.D., Green, J.R., 1995. Microeconomic Theory. New York: Oxford University Press.

McAfee , P.R., McMillan, J., 1989. Government procurement and international trade. Journal of International Economics 26(3-4) 291-308.

Mouwen, A., Rietveld, P., 2012. Does competitive tendering improve customer satisfaction with public transport? A case study for the Netherlands. VU University working paper.

Rothkopf, M.H., Harstad, R.M., Fu , Y., 2003. Is subsidizing inefficient bidders actually costly? Management Science 49(1), 71-84.

Singh, R., (1998). Takeover bidding with toeholds: the case of the owner's curse. The Review of Financial Studies 11(4), 679-704.

Verhoef, E.T., 2007. Second-best road pricing through highway franchising. Journal of Urban Economics 62(2), $337-361$. 